DOI: $10.4274 /$ jarem.galenos.2020.3275

J Acad Res Med 2020;10(3):283-87

\title{
Relationship of Endometrial Polyp Prediction with Clinical and Demographic Findings
}

\author{
(1) Dilşad Herkiloğlu1, (1) Şefik Gökçe1, (1) Pınar Göksedef1, (1) Canan Kabaca2, (1) Gülhan Sağıroğlu2 \\ ${ }^{1}$ Yeni Yüzyıl University, Private Gaziosmanpaşa Hospital, Clinic of Gynecology and Obstetrics, İstanbul, Turkey \\ 2University of Health Sciences Turkey, Zeynep Kamil Gynecology and Child Diseases Training and Research Hospital, Clinic of Gynecology \\ and Obstetrics, İstanbul, Turkey
}

Cite this article as: Herkiloğlu D, Gökçe Ş, Göksedef P, Kabaca C, Sağıroğlu G. Relationship of Endometrial Polyp Prediction with Clinical and Demographic Findings. J Acad Res Med 2020;10(3):283-87

\begin{abstract}
Objective: Endometrial polyp (EP) can be diagnosed clinically by transvaginal ultrasonography (TVUSG). In our study, we aimed to show the effectiveness of TVUSG in detecting EP with the hysteroscopy $(\mathrm{H} / \mathrm{S})$ results of patients who applied to our clinic and were considered for EP in TVUSG.

Methods: One hundred twenty-five patients who were admitted to the obstetrics outpatient clinics of our hospital between August 1, 2015 and April 1, 2017 and were scheduled for H/S operation with a pre-diagnosis of EP were included in the study. The relationship between the age, abnormal uterine bleeding (AUB), infertility history, and the presence of EP after $\mathrm{H} / \mathrm{S}$ was examined in the patients who had EP appearance on ultrasonography. The H/S results of patients with suspected EP in TVUSG and the efficiency of TVUSG in detecting EP were investigated.

Results: The average age of the patients was $38.04 \pm 8.47$ and ranged from 21 to 63 . A significant difference was found in $\mathrm{H} / \mathrm{S}$ between the ages of those with polyps and those without them ( $p=0.012$ ). In patients with polyps in $H / S$, the average endometrium thickness was $13.36 \pm 5.37 \mathrm{~mm}$, and in non-polyps, endometrium thickness was $14.08 \pm 4.58 \mathrm{~mm}$. There was no significant difference in terms of endometrial thickness $(p=0.141)$. The rate of AUB history (34.5\%) in those with polyps seen in $\mathrm{H} / \mathrm{S}$ was significantly higher than the rate of AUB history (13.2\%) in those without polyps ( $p=0.007)$. Polyps were observed in $\mathrm{H} / \mathrm{S}$ in $76 \%$ of 73 cases aged $>35$, and this rate was found to be significantly higher than cases under 35 years old. The sensitivity and negative predictive value was the highest in the diagnosis of polyp in the case of $>35$ years old alone $(64.3 \%$ and $76.7 \%$, respectively); Specificity and positive predictive value were the highest in both AUB and $>35$ years of age $(89.4 \%$ and $85.7 \%$, respectively).

Conclusion: With TVUSG, the diagnosis of EP can be made with high accuracy in the presence of over 35 years of age with AUB findings.

Keywords: Hysteroscopy, endometrial polyp, abnormal uterine bleeding
\end{abstract}

ORCID IDs of the authors: D.H. 0000-0001-9915-3469; Ş.G. 0000-0003-0939-4539; P.G. 0000-0002-2163-6329; C.K. 0000-0002-7069-279X; G.S. 0000-0002-0334-1260. 


\section{INTRODUCTION}

Endometrial polyps (EP) are benign lesions that rarely show malignancy, resulting from hyperplasia of the endometrial gland and stroma. Although it is seen at all ages, it is most often observed in women between the ages of 40-55. EP is diagnosed in patients as a result of complaints of menometroragia, pelvic pain, infertility and perimenosal vaginal bleeding (1).

The prevalence of EP ranges from $7.8 \%$ to $34.9 \%$, depending on the population studied $(2,3)$. Intrauterine evaluation is performed by ultrasonography, hysterosalpingography, saline infusion sonography (SIS), hysteroscopy (H/S) and magnetic resonance imaging. Transvaginal ultrasonography (TVUSG) is a method with high accuracy for the uterine cavity $(4,5)$. Although SIS has a higher diagnostic rate, patients can ultimately be referred to $\mathrm{H} / \mathrm{S}$ (6). The improved diagnostic accuracy of the polyp by various methods has led to the increase in the use of $\mathrm{H} / \mathrm{S}$, which proves the best diagnosis and treatment approach.

We aimed to show the efficacy of TVUSG in detecting EP by examining the relationship between the presence of EP after $(\mathrm{H} / \mathrm{S})$ in patients with abnormal uterine bleeding (AUB), a history of infertility and EP appearance on ultrasonography.

\section{METHODS}

One hundred twenty-five patients who were admitted to the obstetrics outpatient clinics of our hospital between August 1, 2015 and April 1, 2017 with a pre-diagnosis of EP and scheduled for $\mathrm{H} / \mathrm{S}$ operation were included in the study. Patients with complaints of deterioration in their previous menstrual pattern, sudden increase in the number of pads they used during the day, 3 or more days of deviation from normal menstruation periods, and a change of 4 days or more between menstruations were evaluated as AUB. Endometrial thickness was evaluated with a voluson GE brand 4-8 $\mathrm{mHz}$ wide-band Vaginal Probe in any phase of the menstrual cycle. With TVUSG, external-external measurements were made from the endometrium and myometrium border passing through the midline of the uterus in the sagittal plan, including the anterior and posterior layers, without including fluid deposits in the cavity. If the endometrium is seen to be thickened in a certain cross section, more hyperechogenic than normal endometrium and focal thickness increases that do not exceed the junction of the endometrium and myometrium, this situation is defined as the presence of polyps in the endometrial cavity. $\mathrm{H} / \mathrm{S}$ indication was given to patients with suspected polyp. Age, gravida, parity and endometrium thickness of patients were retrospectively scanned from their files. All patients were given general anesthesia between the $6^{\text {th }}$ and $12^{\text {th }}$ days of the cycle, and after cervical dilation in the lithotomy position, $90^{\circ}$ loop electrodes were entered into the uterine cavity with hysteroscope. Cervical canal, cavity and both tubal ostium were examined. All the polyps that were monitored were resected and sent to pathology. Postoperative complications did not develop in patients undergoing surgery. The study was approved by the University of Health Sciences Turkey, Zeynep Kamil Obstetrics and Pediatrics Training and Research Hospital Clinical Research Ethics Committee (approval number: 89, date: 21.04.2017). Informed consent was obtained from each patient before the study.

\section{Statistical Analysis}

SPSS 24.0 (IBM Corporation, Armonk, New York, United States) program was used to analyze the variables. The suitability of the data for normal distribution was evaluated by the Shapiro-Wilk test, and the homogeneity of variance was evaluated by the Levene test. The Independent Samples t-test was used with Bootstrap results, while the Mann-Whitney $U$ test was used with the Monte-Carlo simulation technique to compare groups with and without polyps in $\mathrm{H} / \mathrm{S}$ with each other according to quantitative data. Pearson chisquare tests, Monte-Carlo Simulation technique and Exact results were used in comparing those with and without polyps in $\mathrm{H} / \mathrm{S}$ with each other according to categorical variables, and the column ratios were compared with each other and expressed according to the Benjamini-Hochberg corrected $p$-value results. Sensitivity and specificity for cutoff calculated to distinguish between polyps and non-polyps in H/S by age were examined and expressed by receiver operating characteristic curve analysis. The variables were examined at $95 \%$ confidence order, and p-value less than 0.05 was considered significant.

\section{RESULTS}

The study included 125 patients. Demographic characteristics of patients are shown in Table 1. The average age of the patients was $38.04 \pm 8.47$ and ranged from 21 to 63 . AUB was present in $28 \%$ of cases. The rate of cases diagnosed with infertility was $22.4 \%$ ( $n=22)$. In the study of pathology results of 125 patients, endometrial hyperplasia was observed on the ground of EP in only 1 of them.

The number of polyps in H/S was 87 (69.9\%). The average age of 87 patients who were monitored for polyps in $\mathrm{H} / \mathrm{S}$ was $39.25 \pm 8.27$, and the average age of 38 patients who were not monitored for

\begin{tabular}{|l|l|}
\hline Table 1. Demographics & $\mathbf{n = 1 2 5 , ( \% )}$ \\
\hline Age (mean \pm SD) & $38.04 \pm 8.47$ \\
\hline Endometrium thickness (mm) & $13.45 \pm 0.25$ \\
\hline Gravida median (range) & $2(0-12)$ \\
\hline Parity median (range) & $1(0-11)$ \\
\hline Living median (range) & $1(0-11)$ \\
\hline Presence of AUB & $35(28 \%)$ \\
\hline Infertility & $28(22.4 \%)$ \\
\hline Presence of polyp & $87(69.9 \%)$ \\
\hline SD: standard deviation, AUB: abnormal uterine bleeding
\end{tabular}


polyps was $35.26 \pm 8.36$. A significant difference was found in $\mathrm{H} / \mathrm{S}$ between the ages of those with polyps and those without them $(p=0.012)$. In patients with polyps in $H / S$, the average endometrium thickness was $13.36 \pm 5.37 \mathrm{~mm}$, and in non-polyps, endometrium thickness was $14.08 \pm 4.58 \mathrm{~mm}$. No significant differences were found in endometrium thickness $(p=0.141)$.

In 30 of the 35 patients with AUB, EP was monitored at H/S. AUB history rate (34.5\%) was significantly higher in those who showed polyps in $\mathrm{H} / \mathrm{S}$ than in those who did not show polyps (13.2\%) $(p=0.007)$. In $76 \%$ of 73 cases with an age of $>35$, polyps were monitored at $\mathrm{H} / \mathrm{S}$, and this rate was significantly higher than in cases under the age of 35 . The incidence of polyps in patients with suspected EP and infertility in TVUSG was not monitored differently from others ( $p=0.467$ and 0.246 , respectively) (Table 2). In 28 (22.4\%) of cases, both AUB and $>35$ years of age were present. AUB complaint and the simultaneous presence of $>35$ years of age were significantly associated with the presence of polyps compared to others $(p=0.035)$.

Sensitivity, specificity, positive predictive value (PPV) and negative predictive value (NPV) values in polyp diagnosis of the presence of $A U B,>35$ years of age and both at the same time are summarized in Table 3. Only $>35$ years of age was the highest sensitivity and NPV in the diagnosis of polyps (64.3\% and $76.7 \%$, respectively); specificity and PPV were the highest if both AUB and $>35$ years of age $(89.4 \%$ and $85.7 \%$, respectively).

\section{DISCUSSION}

EP is a focal hyperplastic growth of the endometrial glands and stroma. AUB is the most common finding in age groups of reproductive age and postmenopausal age group (2). In many previous studies, $\mathrm{H} / \mathrm{S}$ has been shown as the gold standard diagnostic and treatment method in patients with AUB $(7,8)$.
Similarly, in our study, the rate of AUB history in those with polyps in $\mathrm{H} / \mathrm{S}$ was found to be significantly higher than the rate of AUB history in those without polyps. In addition to being therapeutic, $\mathrm{H} / \mathrm{S}$ has become superior to other methods when evaluated in terms of affecting quality of life and cost.

TVUSG can be considered as a first-line examination method by its two-dimensional imaging of the uterine cavity. But it should be considered that it has noticeably poor sensitivity and specificity compared to SIS. The effectiveness of SIS in the diagnosis of focal lesions increases by imaging both the uterine cavity and myometrium. SIS stands out compared to H/S, which is an invasive procedure, due to its easy applicability, tolerability, low cost and outpatient applicability. $\mathrm{H} / \mathrm{S}$ is the gold standard in the pathologies of the uterine cavity in all imaging methods, including SIS, as it allows the treatment of detected lesions in the same session, even if it is considered an alternative to H/S. Ragni et al. (6), in their study including 98 infertile patients, took $\mathrm{H} / \mathrm{S}$ as the gold standard and compared SIS with TVUSG. At the end of the study, they reported that SIS has a higher diagnostic rate than TVUSG in intrauterine pathologies. When compared with $\mathrm{H} / \mathrm{S}$, the sensitivity of SIS was $98 \%$ and specificity was $95 \%$, and the sensitivity of TVUSG was $91 \%$ and specificity was $83 \%$. Due to the low diagnostic values of SIS in lesions such as endometrial hyperplasia, endometrial cancer and endometritis, histopathological diagnosis with endometrial biopsy is required in suspicious cases.

TVUSG is recommended to be used for pre-evaluation in patients with AUB (7). However, it has been observed that $24 \%$ of polyps can be missed with TVUSG (8). In our study, the rate of polyp incidence as a result of $\mathrm{H} / \mathrm{S}$ performed on patients with a clinical diagnosis of EP in TVUSG was observed as $69.6 \%$. Demirtaş et al. (9) confirmed the diagnosis of EP in 95 (70.9\%) of 130 patients with a pre-diagnosis of $E P$, by performing $H / S$ and dilatation and

\section{Table 2. Distribution of endometrial polyps by clinical and demographic data}

\begin{tabular}{|l|l|l|l|l|}
\hline Polyp in hysteroscopy & No $38(30.4 \%)$ & Yes $87(69.6 \%)$ & Total $125(100 \%)$ & $p$ \\
\hline Age $>35$ & $17(23.3)$ & $56(76.6)$ & $73(58.4)$ & 0.041 \\
\hline AUB & $5(14.3)$ & $30(85.7)$ & $35(28.0)$ & 0.007 \\
\hline Polyp suspicion at USG & $11(26.2)$ & $31(73.8)$ & $42(33.6)$ & 0.467 \\
\hline History of infertility & $11(39.2)$ & $17(69.6)$ & $28(22.4)$ & 0.246 \\
\hline AUB and age $>$ 35 & $24(14.3)$ & $4(85.7)$ & $28(22.4)$ & 0.035 \\
\hline
\end{tabular}

AUB: abnormal uterine bleeding, USG: ultrasonography

Table 3. presence of AUK, $>35$ years of age and simultaneous values of both in polyp diagnosis

\begin{tabular}{|c|c|c|c|c|}
\hline & Sensitivity & Specificity & PPV & NPV \\
\hline AUB & $34.4 \%$ & $86.8 \%$ & $85.7 \%$ & $36.6 \%$ \\
\hline Age $>35$ & $64.3 \%$ & $55.2 \%$ & $76.7 \%$ & $40.3 \%$ \\
\hline AUB and age $>35$ & $27.5 \%$ & $89.4 \%$ & $85.7 \%$ & $35.1 \%$ \\
\hline
\end{tabular}


curettage. In our study, although the diagnosis was confirmed only by $\mathrm{H} / \mathrm{S}$, we attribute our lower rates to TVUSG quality and operator differences in the pre-diagnosis evaluation.

In a metaanalysis covering 51 studies on the malignancy potential of EP, malignancy rates in EP were found to be $0-15 \%$ (10). In a study associated with EP and malignancy, 516 EP were excised with $\mathrm{H} / \mathrm{S}$ and histopathologically $96.9 \%$ were benign, $1.2 \%$ were premalignant, and $1.9 \%$ were malignant (11). In our study, we did not observe malignancy in the histopathological diagnosis, only one patient had endometrial hyperplasia. Since endometrial hyperplasia is considered as a premalignant lesion, we found similar rates in our study.

The prevalence of EP increases with age. In the study of Ricciardi et al. (12), 79.8\% of women were under 60 years old. In the practical report of the American Association of Gynecological Laparoscopists, it was stated that increasing age is a risk factor for EP (13). In our study, polyps were monitored at $\mathrm{H} / \mathrm{S}$ in $76 \%$ of 73 cases with an age of $>35$, and this rate was significantly higher than in cases under the age of $35(p=0.041)$. Only $>35$ years of age was the highest sensitivity and NPV in the diagnosis of polyps (64.3\% and $76.7 \%$, respectively); specificity and PPV were the highest if both AUB and $>35$ years of age $(89.4 \%$ and $85.7 \%$, respectively). Thus, when this age group applies to gynecology clinics, the possibility of diagnosing EP increases, but it will save time for diagnosis and treatment.

In a study by Hassa et al. (14), 29.2\% of the patients had multiple polyp, and in another study by Arıcı et al. (15), it was found that the number, location, and size of the polyps were not related to the patients' findings. In a study conducted by Preutthipan and Herabutya (16), the average size of the polyp in premenopausal women was $3.4 \pm 0.9 \mathrm{~cm}$, and it was found to be $2.5 \pm 0.8 \mathrm{~cm}$ smaller than postmenopausal women. When the polyp area was examined, the right or left sidewalls, common locations, followed by the anterior and posterior walls. This situation can be considered as one of the causes of infertility in women with polyps that obstruct tubal osteosis. EP can cause infertility, especially in the cornual area. In our study, no statistically significant relationship was found between infertility and polyps in $\mathrm{H} / \mathrm{S}(\mathrm{p}=0.246)$. However, EP was monitored in 17 (69.6\%) of 28 patients who were infertile. In the study of Shokeir et al. (17), EPs were diagnosed hysteroscopically in $4 \%$ of all women with unexplained infertility and $14.8 \%$ of infertile women with amenorrhea. We can attribute our higher rate to a small number of patients admitted to a gynecology clinic. As a result, successful results can be achieved for infertile patients with $\mathrm{H} / \mathrm{S}$, which is more convenient in terms of time and cost.

\section{CONCLUSION}

AUB is the most common symptom in patients monitored by EP. EP can be diagnosed with high accuracy if they are over 35 years of age and have a combination of AUB findings. Although $\mathrm{H} / \mathrm{S}$ is the most valuable diagnostic and treatment method in EP diagnosis,
TVUSG should be the first option for preliminary evaluation in terms of cost and convenience.

Ethics Committee Approval: The study was approved by the University of Health Sciences Turkey, Zeynep Kamil Obstetrics and Pediatrics Training and Research Hospital Clinical Research Ethics Committee (approval number: 89 , date: 21.04 .2017 )

Informed Consent: Informed consent was obtained from each patient before the study.

Peer-review: Externally peer-reviewed.

Author Contributions: Surgical and Medical Practices - Ş.G.; Concept - S..G.; Design - D.H.; Data Collection and/or Processing - G.S.; Analysis and/ or Interpretation - C.K.; Literature Search - G.S.; Writing Manuscript - D.H., P.G.

Conflict of Interest: The authors have no conflict of interest to declare.

Financial Disclosure: The authors declared that this study has received no financial support.

\section{REFERENCES}

1. Dreisler E, Stampe-Sorensen S, Ibsen PH, Lose G. Prevalence of endometrial polyps and abnormal uterine bleeding in a Danish population aged 20-74 years. Ultrasound Obstet Gynecol 2009; 33: 102-8.

2. Salim S, Won H, Nesbitt-Hawes E, Campbell N, Abbott J. Diagnosis and management of endometrial polyps: a critical review of the literature. J Minim Invasive Gynaecol 2011; 18: 569-81.

3. Timmerman $D$, Verguts $J$, Konstantinovic ML, Moerman $P$, Van Schoubroeck D, Deprest J, et al. The pedicle artery sign based on sonography with color Doppler imaging can replace second-stage tests in women with abnormal vaginal bleeding. Ultrasound Obstet Gynecol 2003; 22: 166-71

4. Jacobs I, Gentry-Maharaj A, Burnell M, Manchanda R, Singh N, Sharma $A$, et al. Sensitivity of transvaginal ultrasound screening for endometrial cancer in postmenopausal women: a case-control study within the UKCTOCS cohort. Lancet Oncol 2011; 12: 38-48.

5. Kazandi M, Akşehirli S, Cirpan T, Akercan F. Transvaginal sonography combined with saline contrast sonohysterography to evaluate the uterine cavity in patients with abnormal uterine bleeding and postmenopausal endometrium more than $5 \mathrm{~mm}$. Eur J Gynaecol Oncol 2003; 24: 185-90.

6. Ragni G, Diaferia D, Vegetti W, Colombo M, Arnoldi M, Crosignani PG. Effectiveness of sonohysterography in infertile patient work-up: a comparison with transvaginal ultrasonography and hysteroscopy. Gynecol Obstet Invest 2005; 59: 184-8.

7. Arslan S, Yüksel K, Samay ÖG, Yeşilyurt H, Yalçın H, Gökmen O. Office hysteroscopy versus transvaginal ultrasonography in the evaluation of patients with excessive uterine bleeding. Gynecol Obstet Reprod Med 2001; 7: 36-40

8. Bakour SH, Jones SE, O'Donovan P. Ambulatory hysteroscopy: evidencebased guide to diagnosis and therapy. Best Pract Res Clin Obstet Gyneacol 2006; 20: 953-75.

9. Demirtaş Ö, Yeniel Ö, Ergenoğlu M, Demirtaş G, Aşkar N. Retrospective analysis of subjects with a clinical diagnosis of endometrial polyposis. Ege J Med 2012; 51: 239-44.

10. Uglietti A, Buggio L, Farella M, Chiaffarino F, Dridi D, Vercellini $P$, et al. The risk of malignancy in uterine polyps: A systematic review and metaanalysis. Eur J Obstet Gynecol Reprod Biol 2019; 237: 48-56.

11. Gregoriou O, Konidaris S, Vrachnis N, Bakalianou K, Salakos N, Papadias $K$, et al. Clinical parameters linked with malignancy in endometrial polyps. Climacteric 2009; 12: 454-8.

12. Ricciardi E, Vecchione A, Marci R, Shimberni M, Frega A, Maniglio P, et al. Clinical factors and malignancy in endometrial polyps. Analysis of 1027 cases. Eur J Obstet Gynaecol Reprod Biol 2014; 183: 121-4.

13. American Association of Gynecologic Laparoscopists. AAGL Practice report: practice guidelines for the diagnosis and management of endometrial polyps. J Minim Invasive Gynaecol 2012; 19: 3-10. 
14. Hassa H, Tekin B, Senses $T$, Kaya M, Karatas A. Are the site, diameter, and number of endometrial polyps related with symptomatology? Am J Obstet Gynaecol. 2006; 194: 718-21.

15. Arıcı B, Cengiz H, Yaşar L, Özdemir IA, Keven MC. The effects of the number, location, dimension and histopathological diagnosis of endometrial polyps on laboratory and clinical findings. Gaziantep Med J 2012; 18: 90-4.
16. Preutthipan S, Herabutya Y. Hysteroscopic polypectomy in 240 premenopausal and postmenopausal women. Fertil Steril 2005; 83: 705-9.

17. Shokeir TA, Shalan HM, El-Shafei MM. Significance of endometrial polyps detected hysteroscopically in eumenorrheic infertile women. J Obstet Gynaecol Res 2004; 30: 84-9. 